Institute of $\mathbf{F}_{\text {ood and }} \mathbf{A}_{\text {gricultural }} \mathbf{S}_{\text {ciences }}$

\title{
Reducing Methyl Bromide Field Application Rates with Plastic Mulch Technology 1
}

J. W. Noling ${ }^{2}$

Fumigants such as methyl bromide and chloropicrin have been used in combination with plastic mulch row covers since the early 1960's for broad spectrum soilborne pest and disease control. Federal label restrictions for use of methyl bromide require the installation of a plastic mulch covering immediately following application. Unfortunately, methyl bromide was officially categorized as a significant contributor to stratospheric ozone depletion and, as a result of that action, is now incrementally scheduled for a complete phase-out January 1, 2005. The incremental phase-out schedule currently being enforced by the U.S. EPA restricts the production and importation of methyl bromide based on methyl bromide use levels established during the baseline year of 1999. The phaseout will proceed as follows: Beginning January 1, 2001, a 50 percent reduction in baseline use levels; Beginning January 1, 2003, a 70 percent reduction in baseline level; followed and terminating January 1, 2005 with a complete phase-out of methyl bromide production and importation. Continued agricultural use of methyl bromide after January 1, 2005 will be dictated by cost and availability of existing supplies.

\section{Plastic Mulch Bed Covers}

The most commonly used plastic mulches in Florida are black and white, low-density polyethylene (LDPE) mulches typically in the range of 0.6 to 1.4 mil thick. Many different colors, thicknesses, and widths of these embossed LDPE plastic mulches are available for agricultural use. In general, the advantages of plastic mulch include: 1) thermal regulation of soil temperature; 2 ) weed suppression; 3 ) increasing the effectiveness of soil applied pesticides; 4) maintenance of bed shape, architecture, and providing drainage; 5) barrier protection of fruit from soil pathogens; 6) minimizes root pruning from tillage operations for weed control; 7) reduces the evaporative loss of water from soil; and 8) minimizes the leaching of fertilizers from the root zone of plants. In general, the plastic mulch layer protects crops from environmental extremes and impact, and serves to accelerate plant growth and increase crop yields.

In addition to the horticultural advantages, plastic mulches also serve to delay the volatilization of fumigant gases like methyl bromide from soil, and reduce emissions into the atmosphere. In practical

1. This document is ENY-046, one of a series of the Entomology \& Nematology Department, Florida Cooperative Extension Service, Institute of Food and Agricultural Sciences, University of Florida. Published: January 2002. For more publications related to horticulture/agriculture, please visit the EDIS Website at http://edis.ifas.ufl.edu/.

2. J. W. Noling, professor, Entomology and Nematology Department, Citrus Research and Education Center, Cooperative Extension Service, Institute of Food and Agricultural Sciences, University of Florida, Lake Alfred, FL 33850. 
reality however, the LDPE mulches in common use today in Florida actually provide little direct physical barrier to the diffusion of methyl bromide through the mulch. The condensation of water on the under surface of the film and the resultant increased moisture content within surface soil appears to be actually more important for slowing the volatilization of methyl bromide from soil than the mulch itself. The water seal which forms on the soil surface acts as a diffusion barrier because diffusion of a gas through water is much less and slower than diffusion through open soil pores. Similarly, beds which are moist and tightly compressed are much more resistant to methyl bromide diffusion than beds which are dry and only loosely compacted or pressed.

\section{Emissions of Methyl Bromide from Agricultural Fields}

In recent years many different experiments have been conducted to obtain information on methyl bromide emissions from bare and mulched soil following field application. Much of this research appears to show that as much as 20 to $90 \%$ of the methyl bromide applied to a given field can ultimately out-gas through the LDPE plastic mulch cover and into the air after soil fumigation. Many different chemical, soil, and environmental factors interact to cause the wide variation of reported emission losses from soil with methyl bromide. In general, the rates in which methyl bromide volatilizes from soil under typically condition are initially high following application and then decrease with time, such that after 5 to 7 days post application, little remains in soil (Figure.1).

After application, volatilization continues as long as methyl bromide remains in the soil and a concentration-difference exists under the plastic and the lower air of the field. In general, a large proportion of the methyl bromide applied, volatilizes from soil within the first 24 to 48 hours following application. Since temperature has such a direct effect, the highest levels of methyl bromide out-gassing typically occurs during the middle of the day when air temperatures are highest and are lowest at night, when air temperatures are coolest. Given the pending phase-out of methyl bromide and reduced supply and increased costs of the gas following each

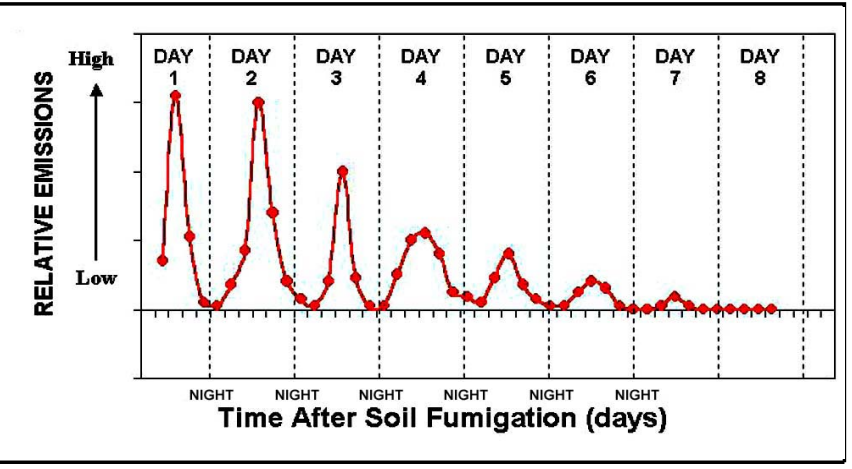

Figure 1. Generalized representation of the relative emissions of methyl bromide volatilizing through a plastic mulch cover with time after initial soil fumigation. Data is plotted only to show general decline in emissions with time, and highest daily rates of emission occurring midday and lowest emissions at night. Besides temperature, other soil and environmental conditions can modify methyl bromide emissions from soil greatly.

incremental stage of the phase-out, the use of higher barrier mulches may make it possible to reduce fumigant application rates by helping to contain the fumigant within the soil and reduce overall emissions into the atmosphere.

\section{Mulch Permeability}

The permeability (the ability to pass through) of a plastic mulch to methyl bromide is based on the thickness, density, and chemical composition of the plastic mulch. Regardless of composition, thicker mulches are generally less permeable to methyl bromide than are thin mulches (Figure 2). In most cases, practical and cost efficiency considerations prevent the use of thicker LPDE mulches for enhanced containment of methyl bromide in soil. Some plastic mulches provide better diffusion barrier to certain fumigants than others. For example, permeability to methyl bromide decreases as the density of a mulch increases. High density polyethylene (HDPE) mulches are less permeable to methyl bromide than LDPE mulches.

In some cases a particular type of film may provide a reasonable barrier for one fumigant but not another. For example, some of the high barrier, high-density polyethylene mulches used in California provide some resistance to methyl bromide and chloropicrin, but were shown to offer little resistance to 1,3-D (Telone) diffusion (Figure 3). MITC, the active ingredient of metam sodium, is even more 


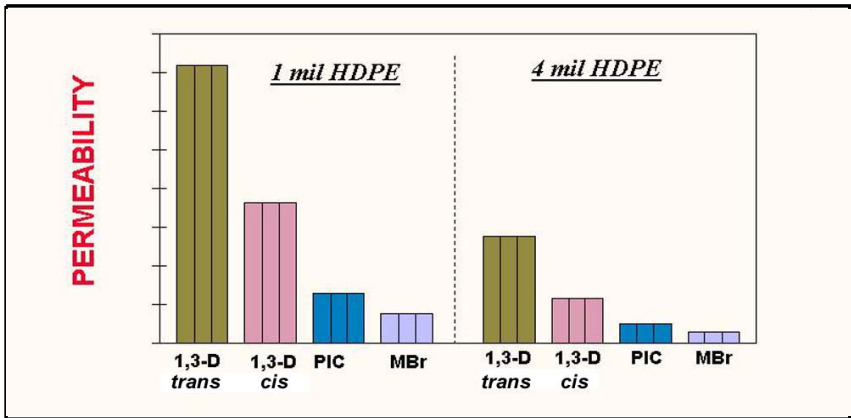

Figure 2. Permeability of methyl bromide (Mbr), Chloropicrin (Plc), and two isomers of 1,3-Dichloropropene (telone) through high density polyethylene (HDPE) plastic mulch of two thicknesses. Taller bars indicate higher permeability.

diffusive than Telone through the HDPE mulch. Virtually impermeable films (VIF) or mulches, allow very little methyl bromide and other fumigant gases to pass through it, and as the name implies, are virtually impermeable. These VIF mulches are typically multi-layer films composed of barrier polymers such as ethylene vinyl alcohol (EVOH) or polyamide (nylon) sandwiched between other polymer layers (typically LDPE) that keep the barrier polymers from swelling. Compared to LDPE mulches, certain VIF's are over 20,000 times less permeable to methyl bromide and other fumigant compounds.

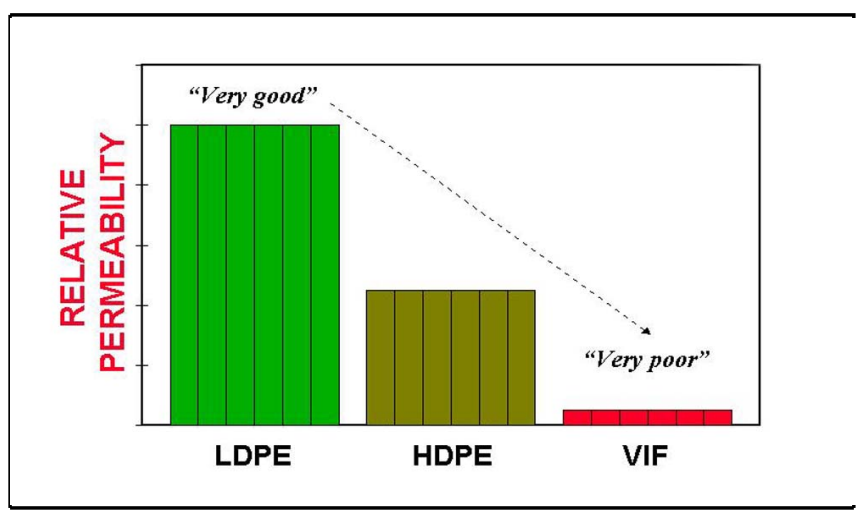

Figure 3. Permeability of gaseous methyl bromide through low-density polyethylene (LDPE), high-density polyethylene (HDPE), and virtually impermeable (VIF) plastic films. Taller bars represent higher permeability.

Research on the use of various types of high barrier mulches to reduce soil application rates and emissions of methyl bromide has been conducted in many different locations around the world. For example, use of virtually impermeable plastic mulches (VIF) has proved to be a simple and effective strategy to reduce soil emissions of not only methyl bromide but of other fumigant gases as well. It is clear from the research that has been conducted with VIF that fumigant use rates can be substantially reduced without serious consequence to pest control efficacy or crop yield response. The results of most of these field studies show that methyl bromide application rates can be reduced by half (50\%) through the use of virtually impermeable or gas-tight films at the time of application. In the short term, this research has also demonstrated that growers may even be able to distribute what methyl bromide they can acquire to adequately treat their existing acreage without incurring significant loss of pest control or yield or to have to completely rely on alternative tactic(s) at this time. The use of these high barrier mulches are not likely to occur without problems however.

\section{Potential Problems with High Barrier Mulches}

Historically VIF mulches have suffered from high cost and from other problems involving tensile strength. They are typically slow to properly install and are subject to tearing (zippering) during machine application in the field. More efficient containment of gases below the mulch also suggests that plantings may have to be delayed to insure soil residues have dissipated and plant injury will not occur. The average price for LDPE mulch is approximately \$250-300/acre, while HDPE mulch is \$400/acre and VIF mulch in the range of $\$ 400$ to 600/acre. The higher price for VIF is partially reflective of transportation costs from European manufacturers. Compared to LDPE, reduced methyl bromide and chloropicrin application rates (as much as 50\%) and use of the VIF mulch will result in lower fumigant costs which may be completely offsetting given the higher pricing for methyl bromide now in reduced supply. In addition to the increased direct cost of the VIF mulch, increased labor costs for slower machine installation of the mulch should probably also be considered. At present, given the slick, non embossed surfaces of the VIF mulch, machine application of the mulch in the field is typically less than 3 miles per hour. Manufacturer research programs are continuing to focus on ways to resolve many of these problems. 
In addition to higher costs per acre, problems of VIF availability also must be considered. VIF mulches are currently manufactured near exclusively in Europe and Israel by various producers. The names and addresses of the principal manufacturers or their U.S. affiliates are listed in Table 1 . As a result of overseas production, users in the United States will likely incur lengthy delays (upwards of 2-3 months) for delivery of ordered products. There is also concern that although the raw materials needed to produce VIF mulches are readily available in the U.S., current European production capacity is not high enough to meet U.S. demands if it were to substantially increase in the future. To resolve future demand, if it materializes, production facilities in the U.S. would have to be established to insure timely supply.

Table 1. Selected Manufacturers of virtually impermeable plastic film (VIF) or mulch.

\begin{tabular}{||l||}
\hline \hline ORGALLOY $\AA$ \\
Atofina Chemical Inc. \\
2000 Market Steet \\
Philadelphia, PA 19103-3222 \\
PH: (215) 419-7000 FAX: (215)419-7591 \\
1 (800) 225-7788 \\
www.atofinachemicals.com \\
\hline BROMOTEC $\AA$ \\
Lawson Mardon Packaging \\
Salterbeck Trading Estates \\
Workington, Cumbria, CA145DX \\
United Kingdom \\
PH: +44 1946 830694 FAX: +44 1946 830199 \\
www.lawsonmardon.com \\
\hline HYTIBAR $\AA$ \\
Klerk's Plastic Products Manufacturing Inc. \\
546 L \& C Distribution Park \\
Richburg, S.C. 29729 \\
PH: (803) 789-4000 FAX: (803) 789-4001 \\
www.klerks.com \\
\hline \hline
\end{tabular}

